\title{
Parasagittal Meningioma surgery
}

\author{
Ashraf ElBadry ${ }^{1}$, Azza Abdelazeez ${ }^{2}$ \\ ${ }^{1}$ Neurosurgery Department; ${ }^{2}$ Pathology Department \\ Faculty of Medicine, Mansoura University Hospital, EGYPT
}

\begin{abstract}
Background: meningioma in parasagittal location represent between 20\%-30\% of meningioma in the cranial cavity. The close relation of it with Superior Sagittal Sinus make its surgical resection is a great challenge to the surgeon to get a good result. Patients \& method: we collected 23 cases of Parasagittal Meningioma cases medical records (including pre-\& postoperative clinical pictures, images plus operative details and complications post operatively) who admitted to neurosurgery dept., Mansoura University Hospital and underwent surgical resection in the period that began in 2010 and ended in 2016. We followed up the cases at least for 6 months. Results: the patient's age varied between $64-35$ years. 16 female \& 7 males. The presenting symptoms was headache (11 patients), fits (6 patients), motor weakness (5 cases), abnormal gait (1 patient) and dizziness ( 1 case). 15 cases had gross total tumor excision while 8 cases showed partial tumor removal. Recurrence rat was in 4 cases (17.4\%) plus two mortality cases. Conclusion: through our series we could detect cardinal factors in prognosis of these cases which included: tumor size, histology, preoperative identification of the venous collateral and preservation of it in the surgical maneuver. The meticulous microscopic surgical technique can augment this goal.
\end{abstract}

Key words: parasagittal, Meningioma, Intracranial hypertension, Superior sagittal sinus

\section{Introduction}

The term parasagittal meningioma (PSM) applies to those tumors involving the sagittal sinus and the adjacent convexity dura and falx. It comprises approximately 19.5 to $45 \%$ of meningiomas in the cranial cavity. The lateral wall of the SSS lateral angle and wall may be invaded partially or completely with presence of tumor inside the lumen of SSS. Or the tumor may grow to partially or completely occlude the sinus. [12]

Parasagittal meningioma represents a challenge to neurosurgeons all over the world [2] especially if invading the superior sagittal sinus (SSS) lumen, bridging vital collaterals encasement or adherence and many of them may be faced by serious vascular sequelae i.e. Venus infarction that lead to sever neurological deficit when they operated in such cases. In some cases, even the superficial 
cortical and intra-diploid veins injury led to the same catastrophe because it represents essential part of venous drainage. [18]

Inspite of Cushing was the first neurosurgeon who operated on (PSM) 1910 [3] and the contribution of others like Olivercrona, Poppen, Hoessly and Logue in addition etc. But still there is no accurate protocol for dealing with these cases $[1,15,16]$. Even there is no general concept letting the surgeon in the light of the pros and cons of radical resection to follow it [4]. On the other hand, many of them prefer subtotal \& partial tumor resection followed by many alternative options like expectance, Gama knife and radiotherapy to reduce surgical morbidity and mortality [7]

The role of well-developed collateral (secondary to complete SSS occlusion) play important role in preferring total meningioma removal [8]

\section{Patients and method}

We collected 23 cases of Parasagittal Meningioma cases with variable degrees of SSS involvement who admitted to neurosurgery dept., Mansoura University Hospital in the period that began in 2010 and ended in 2016 were enrolled in this study. We excluded the cases who did not fulfill all essentials for this series like:

- Incomplete medical records

- Presentation of other comorbidities

- Lost follow up early postoperative

- The cases who presented to us as a recurrent case with primary surgery outside our department

All cases examined neurologically pre-\& post-operative, their images (CT scan, MRI pre and post contrast, Venus MRA and in some cases angiography) had been evaluated to estimate the degree of SSS invasion and select the operative plan beside pathological reports.

We used the Sindhu's classification [18] in assessment of SSS invasion by the tumor (Figure 1) because we assume it is more practical and simple to follow than other classifications like the Merrem-Krause's \& Bonnal-Brotchi's categories. They underwent surgical resection.

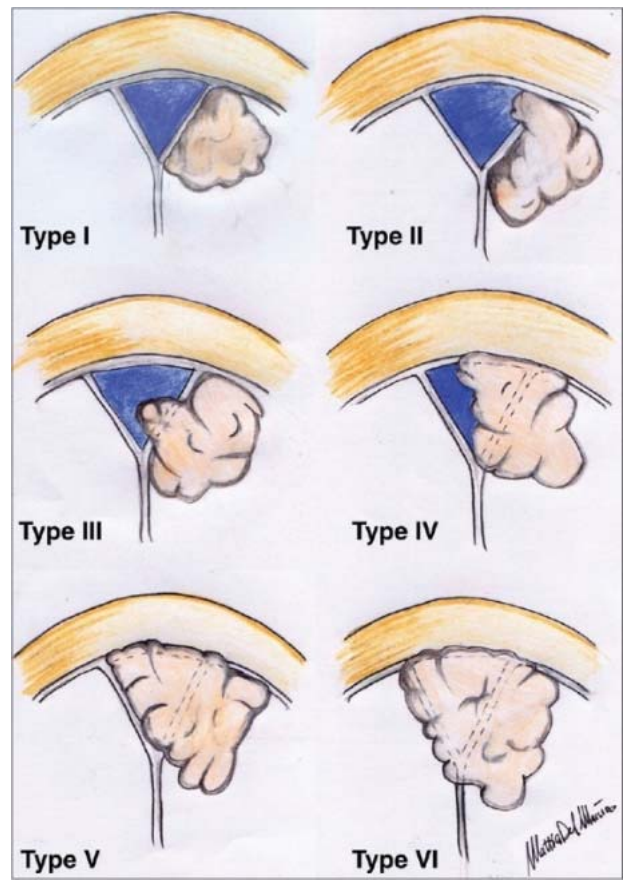

Figure 1 - Sindou's classification in assessment of SSS invasion by the tumor: grade I the tumor attached to the SSS lateral wall, grade II the tumor invades the lateral recess, grade III the tumor invades the SSS lateral wall, grade IV the lateral wall in addition to the roof of SSS have been invaded by the tumor, grade V the whole SSS have been invaded by the meningioma except one of both lateral wall, grade IV the whole SSS have been invaded by the tumor. [18] 


\section{Surgical procedure}

We used anatomical landmarks to estimate the position of SSS in planning the skin incision and operative flap to minimize SSS injury. We did not use any neurophysiological study. All cases monitored intraoperative for air embolism we used central venous catheter to aspirate the air if air embolism occurred intraoperatively. We used mainly two options in reconstruction of the dura layer defect after meningioma removal: galea capitis if the defect is small and fascia lata graft in large dural layer defect.in few cases we used artificial dura mater

Under endotracheal intubation general anesthesia. The position of the patient on operative table was planned according to the meningioma location: if the tumor in the anterior half of the sinus the patients have been placed in supine position, on the other hand, the patient has been placed in prone position if the meningioma was present in posterior half of the SSS. The patient had been held in position by three-point fixation Mayfield

We used mixture of carbocaine $2 \%$ and saline solution for injection sub-dermis and sub-periosteum as first step in galea flap preparation (Figure 2). After skin incision, the galea flap did not exceed the superior temporal line laterally. The craniotomy flap was made according to matching the anatomical land marks in the images and the patient. The craniotomy flap was centered in SSS with rectangular flap with burr holes on SSS both sides (Figure 3). The care must be taken in separation of the dura from the bone flap to avoid SSS injury. Sometimes we saw hypertrophied lacunae as a sequela of hypertrophied venous collaterals. We applied microscope in all cases. Its magnification varied from to 10 to $16 \mathrm{x}$.

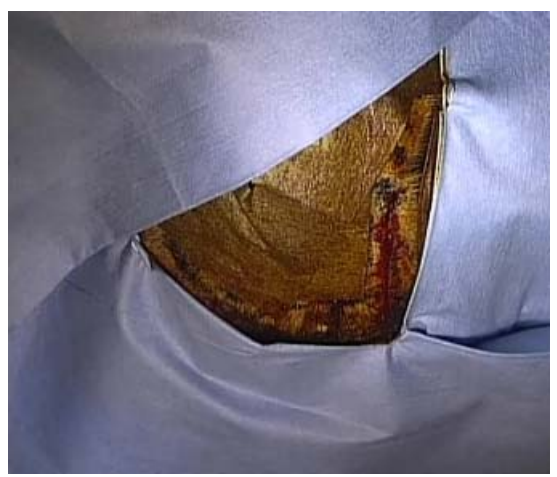

Figure 2 - show the planned skin incision after sub dermis injection with mixture of carbocaine $2 \%$ and saline solution

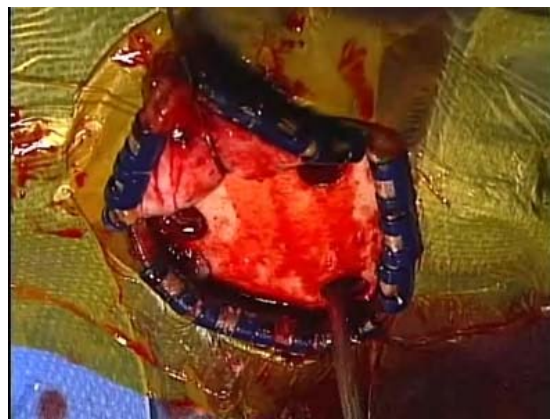

Figure 3 - revealed the burr holes for craniotomy flap was done

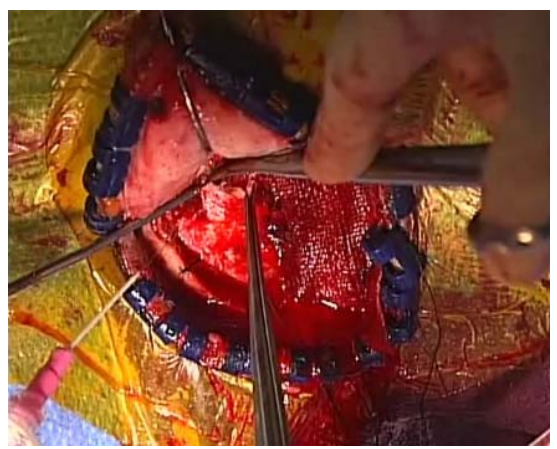

Figure 4 - show the dura opening carefully from lateral to medial to avoid SSS injury \& visualization of bridging veins 


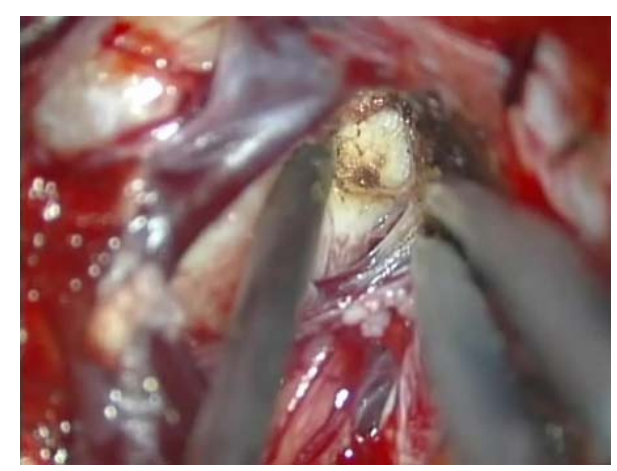

Figure 5 - show coagulation of tumor feeders to reduce the bleeding

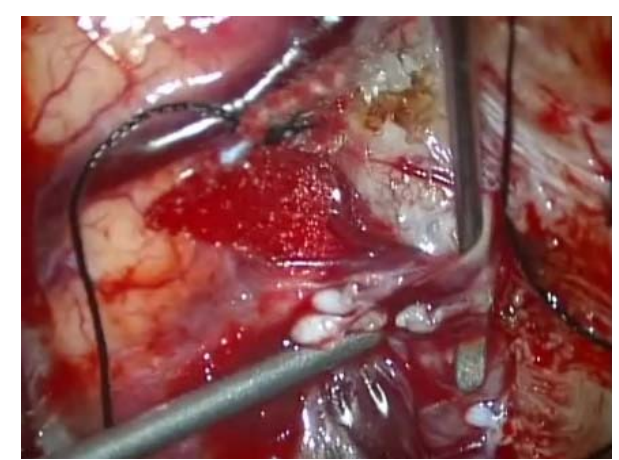

Figure 6 - show identification of collateral veins that creep on tumor capsule (appeared under the microscope hypertrophied, wide caliber attached to SSS) and identifying the tumor brain interface with meticulous dissection

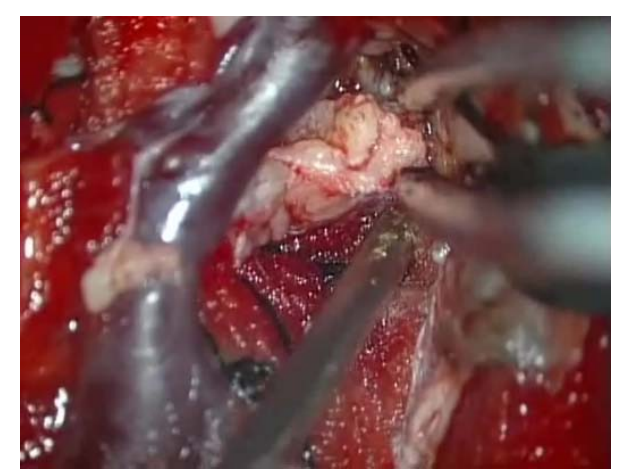

Figure 7 - show freeing the capsule from the surrounding brain tissue

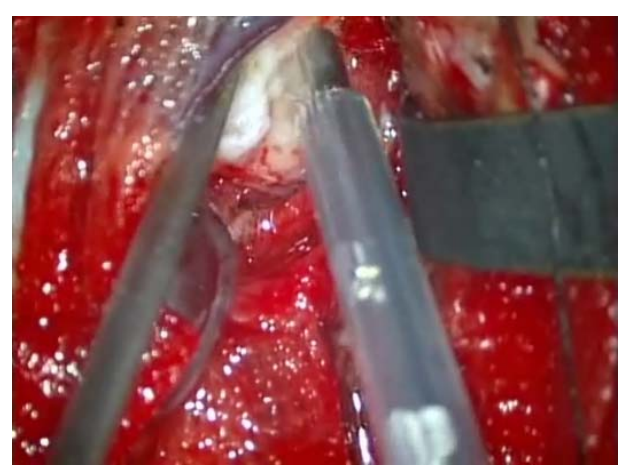

Figure 8 - reveal internal debulking then removing part of PSM capsule using CAUSA

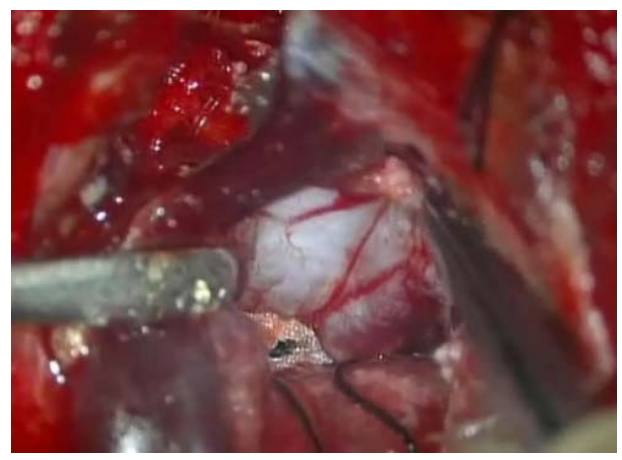

Figure 9 - show freeing the last part of the tumor from the bridging veins which drain in SSS

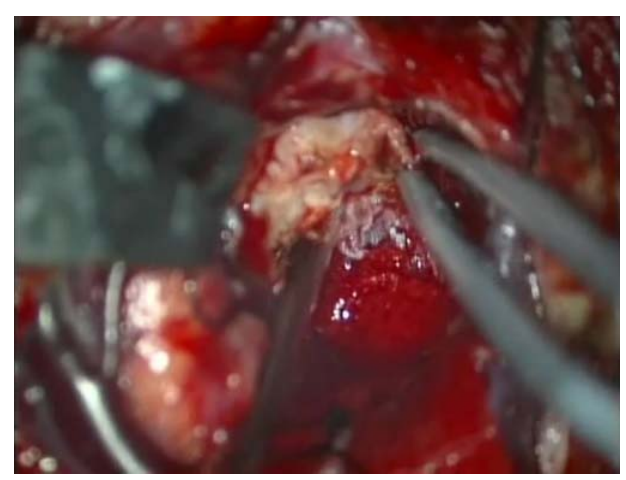

Figure 10 - show dissection of the tumor capsule from the feeder in tumor be brain parenchyma 


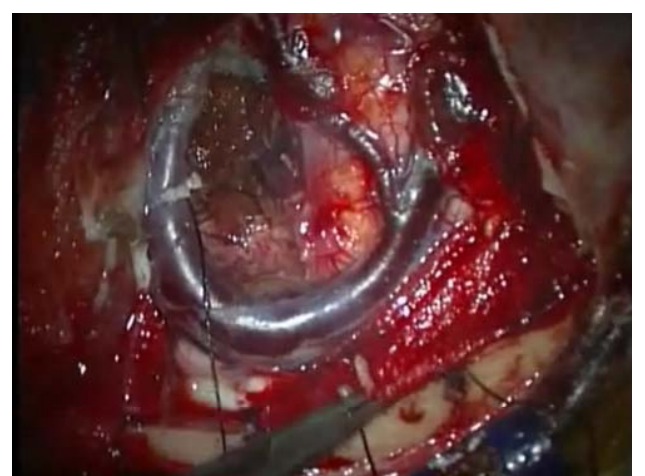

Figure 11 - show the final stage after total excision of the brain tumor and hemostasis of PSM tumor bed

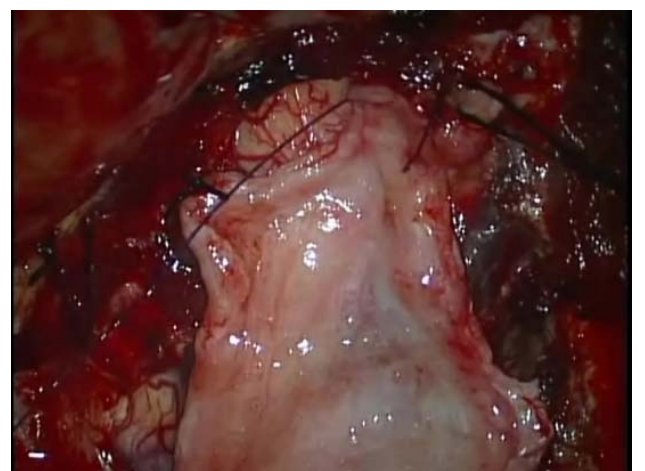

Figure 12 - sow repairing the dural defect with galea capitis patch

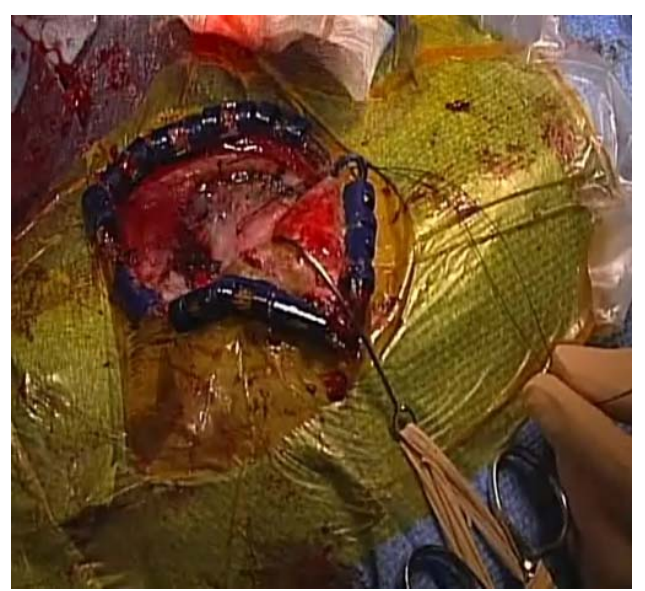

Figure 13 - show water tight suturing the dura mater
The dura opened carefully in the lateral dural flap edge (Figure 4) from posterior forward then open it from lateral to medial making the dural flap base is the attachment to SSS. We began by coagulation the tumor feeders (Figure 5) \& Venus drainage with preservation of collateral veins (that appeared under the microscope hypertrophied, wide caliber attached to SSS and run parallel to it) (Figure 6) as much as possible by early identification under the microscope. the care must be taken to avoid aggressive brain retraction by working inside the meningioma by piecemeal tumor excision (internal tumor debulking) then freeing the capsule from the brain tissue by identifying the tumor brain interface that represent arachnoid plane to reduce pial and brain vessels injury (Figures 7 , $8,9,10)$. We applied wet cotton strips in this plane continuously till complete tumor removal we did not apply. The pericallosal and callosomarginal arteries must be visualized and gently dissected from (PSM) medial inferior surface then the involved part of the falx could be excised safely. Finally, we removed the meningioma part that invaded the SSS if possible. the grade of tumor on Sindou's classification [18] determined the management of SSS involvement: category I there is line of cleavage between the meningioma and the SSS leaving it intact, in grade II we followed the tumor part of the lateral recess then suture the defect in the SSS, in grade III we removed the tumor with simple reconstruction of SSS by galea capitis if possible or subtotal tumor excision was applied leaving the tumor remnant that adhered to the SSS, in grade IV, V we preferred subtotal resection while in grade VI 
we removed the whole tumor in addition to the SSS involved part with occlusion of it preremoval to avoid embolism. We removed the involved part of the falx to reduce the recurrence. We controlled the tumor bed blood oozing by hemostatic materials after blood pressure normalization for at least 10 minutes (Figure 11). At the end of the procedure we reconstruct the dural defect by galea capitis flap
(Figures 12 and 13) if it was small and fascia lata graft if it was large in most cases but few were reconstructed by artificial dura mater, sometimes we used autologous abdominal fat to close the defect also. If we removed the bone that invaded by the tumor (Figure 14) we used titanium mesh and mini-screws to cover the bone defect. (Figures 15, 16)

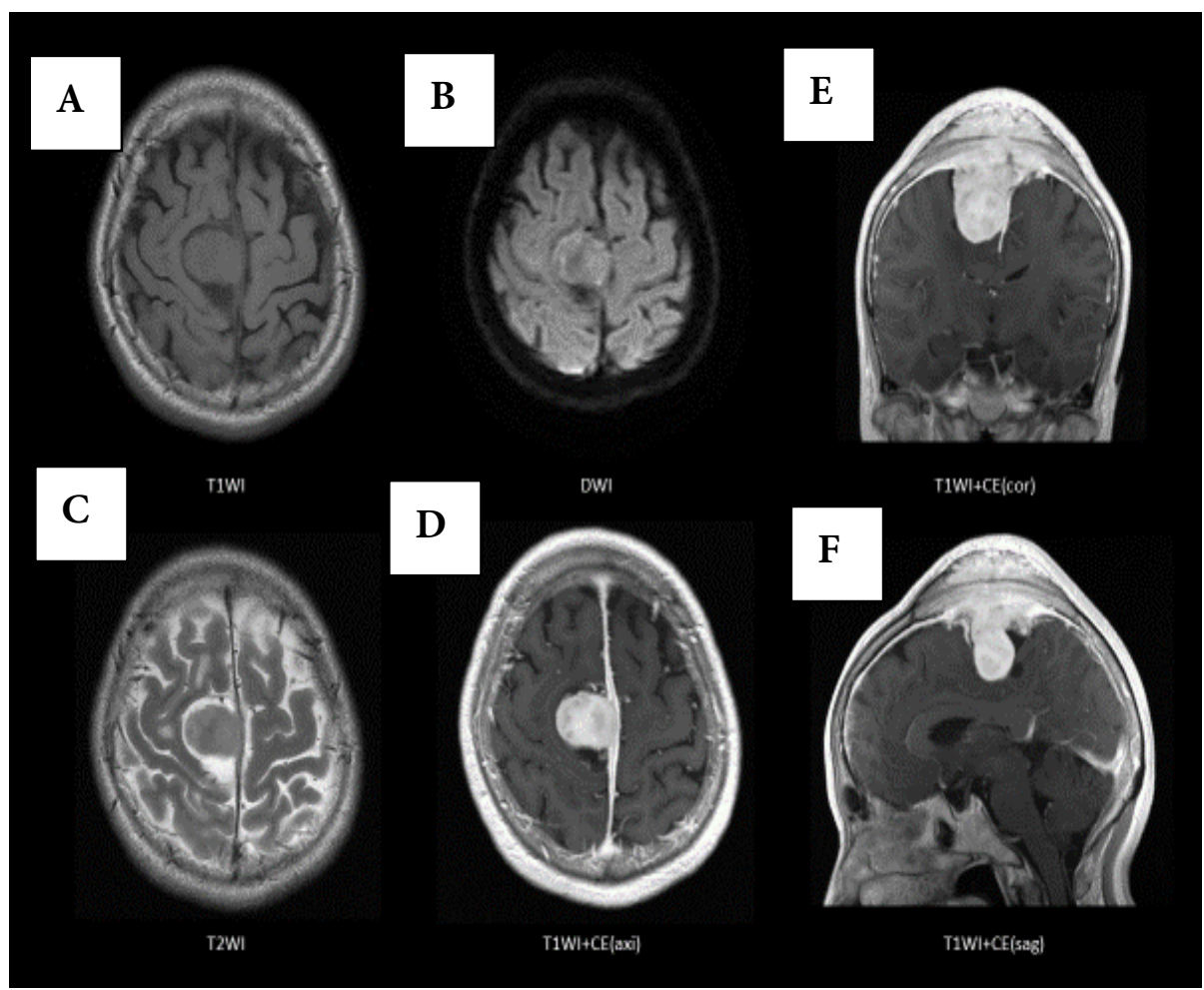

Figure 14 - MRI of PSM Cases: A \&B TIWI axial cut, C T2WI axial cut, D T1WI axial cut with contrast. E T1WI with contrast coronal cut. F T1WI with contrast sagittal cut. Reveal invasion \& occlusion of SSS and Calvarial skull bone erosion over it 


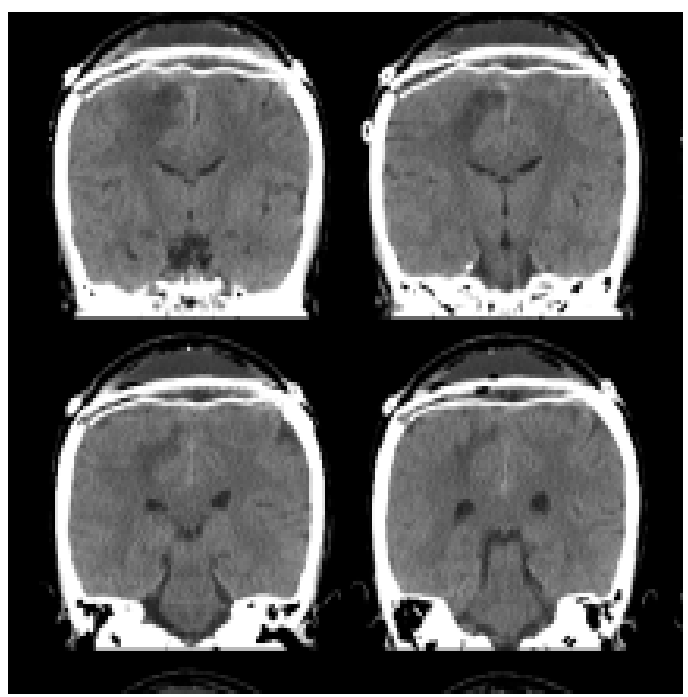

Figure 15 - CT Brain coronal cuts show the titanium mesh covering the bone defect that was invaded by tumor and excised with the tumor

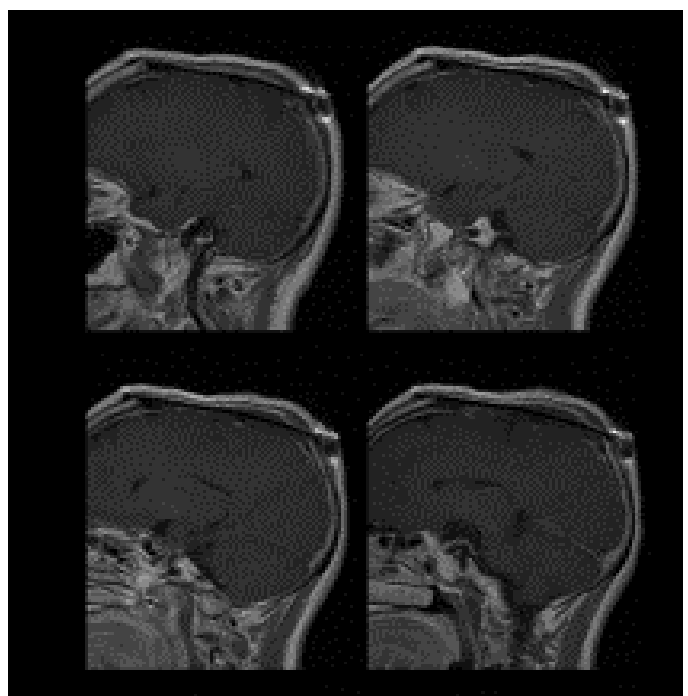

Figure 16 - MRI Brain sagittal cuts show the mesh covering the bone defect that was invaded by tumor and excised with the tumor
We used dexamethasone intraoperatively and for one week postoperative. Beside antibiotic, Manitol, loop diuretic and phenytoin were routinely administrated to these patients. For all cases, low molecular weight heparin was administered for all patients more than 3 weeks postoperatively; we recommend antiplatelet therapy after hospital discharge.

In normal course of the cases we requested MRI Brain pre-\& post contrast plus Venus MRA after three months (unless complication occurred we requested it earlier) then every 6 months interval.

We followed up the cases at least for 6 months clinically and radiologically. We began the patients follow up two weeks after discharge from the hospital then every two months intervals for the first six months. After that we followed them annually. The mean follows up period was 3.2 years. We exclude all cases who did not have adequate follow up file data.

\section{Presenting cases}

Case 1: 62 years old male presented with persistent headache not respond to simple analgesics followed by seizures, on neurological examination mild right hemiparesis. images showed $3 \mathrm{CM}$ diameter tumor size in the middle third of SSS (Figure 17) that took feeder from left middle meningeal artery (Figure 18) and had multiple Venus twigs toward SSS which is patent (Figure 19) 


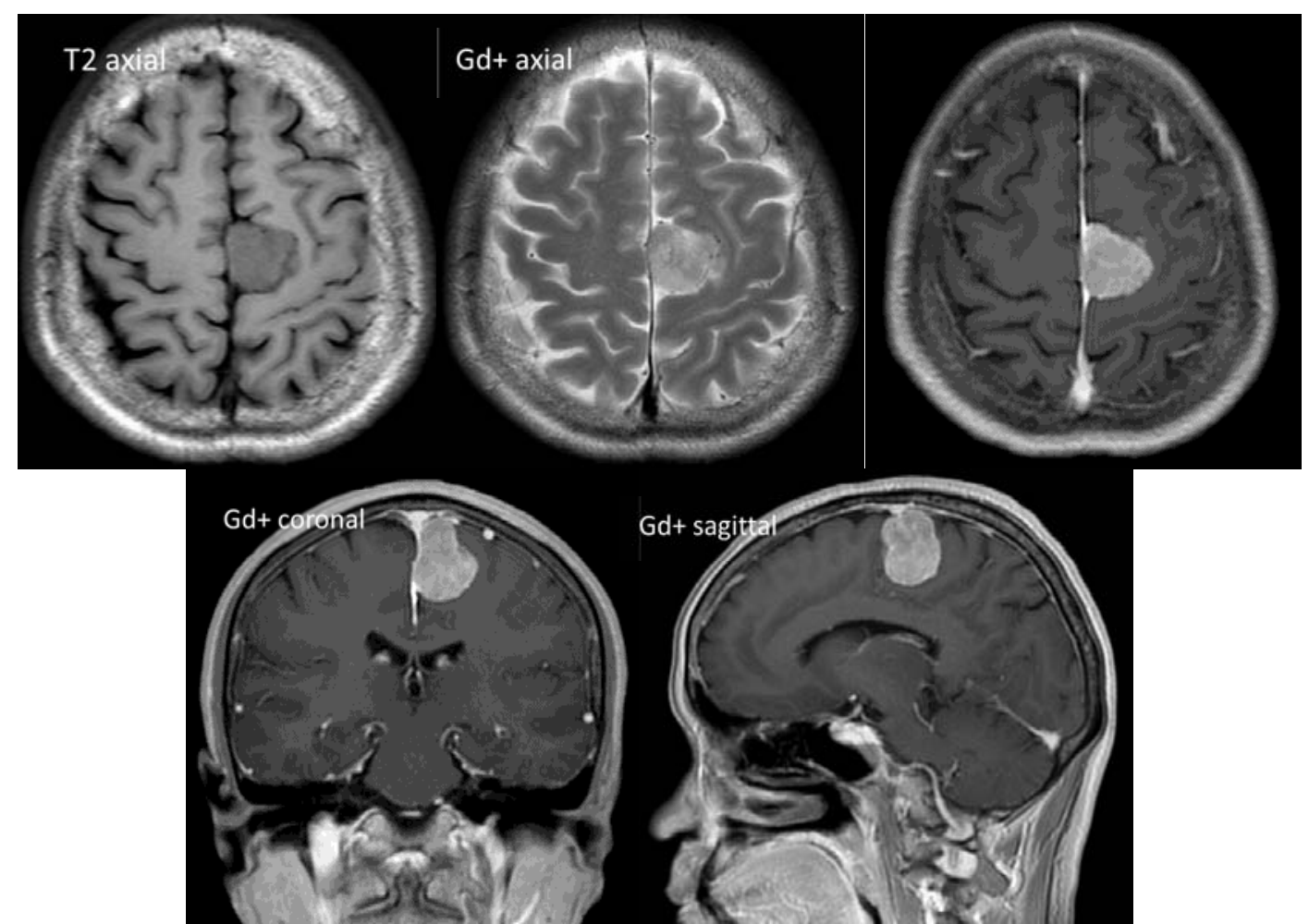

Figure 17 - MRI Brain: axial (T1WI, T2WI, T1WI with contrast), coronal cut T1WI with contrast and sagittal T1WI with contrast showed middle third SSS left parasagittal meningioma grade III on Sindou's classification

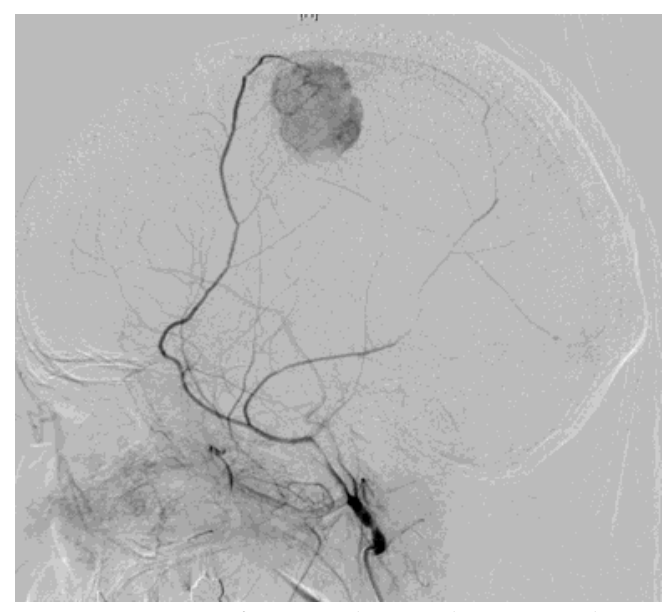

Figure 18 - Left external carotid angiography revealed prominent feeder from left middle meningeal artery

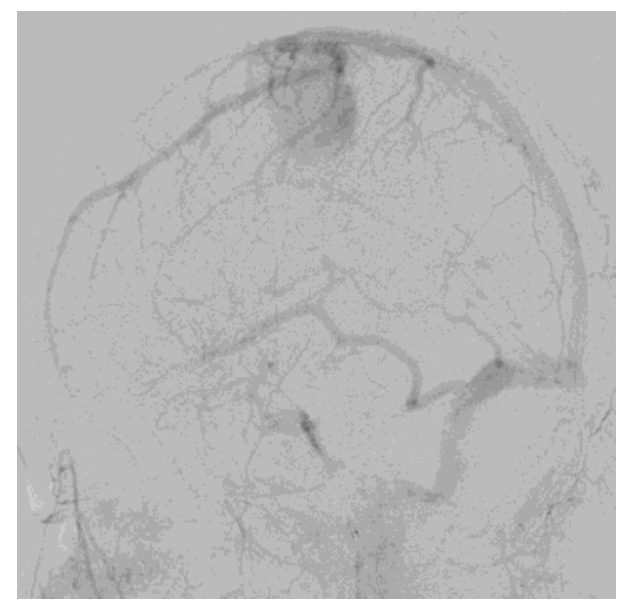

Figure 19 - Left common carotid angiography Venus phase revealed prominent multiple Venus drainage twigs from the tumor toward SSS from left middle meningeal artery 
In the surgery: the patient was placed in Supine position Head up 20 Head median position vertex up $10^{\circ}$, we applied curved skin incision so that the skin flap became about 5 * $5 \mathrm{CM}$ with its center $2 \mathrm{~cm}$ behind Bregma. The surgical procedure was done under the microscope with coagulation of the tumor feeders from left middle meningeal artery to reduce the bleeding and tumor venous drainage to SSS also have been occluded then we peeled the tumor from the SSS after internal debulking in piecemeal way. we saw some feeders from ACA as a result of arachnoid layer tumor invasion toward brain parenchyma. Simpson Grade 2 have been achieved in this case (Figure 20,21).

Case 2: female patient 53 years old presented by headache and progressive Left hemiparesis till motor power became grade 3 it worsens in left upper limb followed by left lower one MRI Brain pre and post contrast revealed showed middle third SSS right parasagittal meningioma grade II on Sindou's classification (Figure 22). The right internal carotid artery and both external carotid arteries feeding the tumor with high blood flow without SSS occlusion (Figure 23).

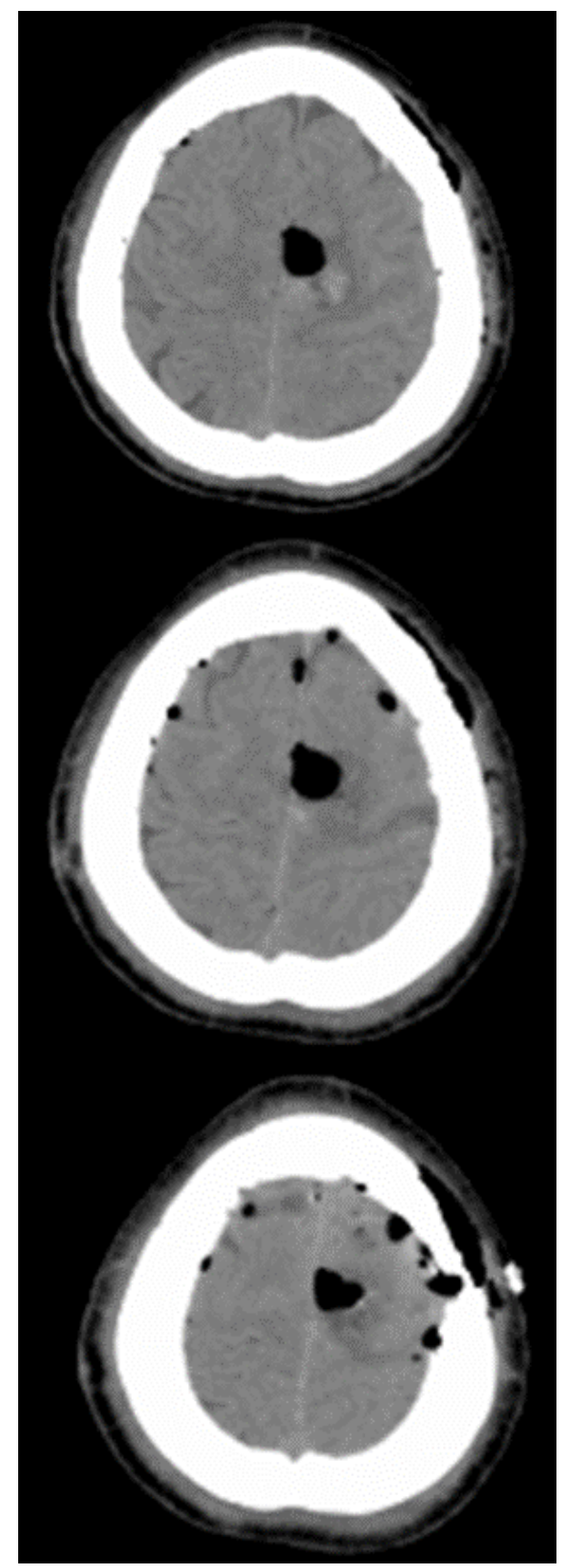

Figure 20 - post operative CT Brain scan axial cuts show grossly total excision of the tumor with some Pneomocephalous in tumor bed 


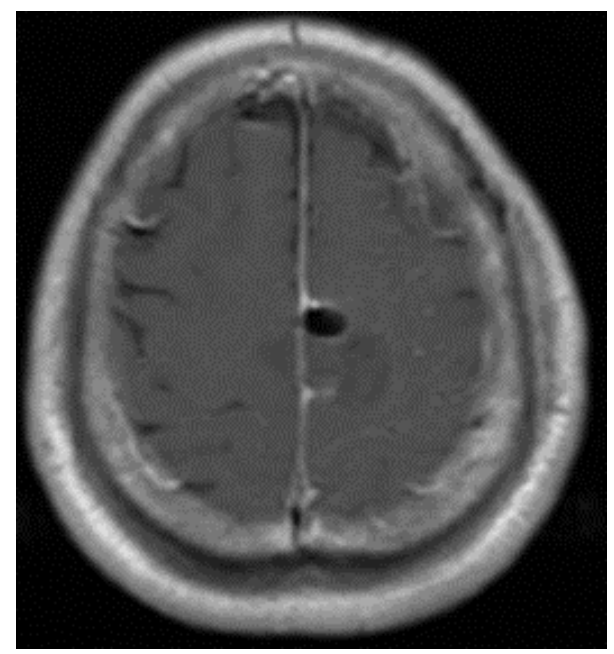

Figure 21 - MRI Brain scan T1WI with contrast axial cuts show grossly total excision of the tumor with some Pneomocephalous in tumor bed

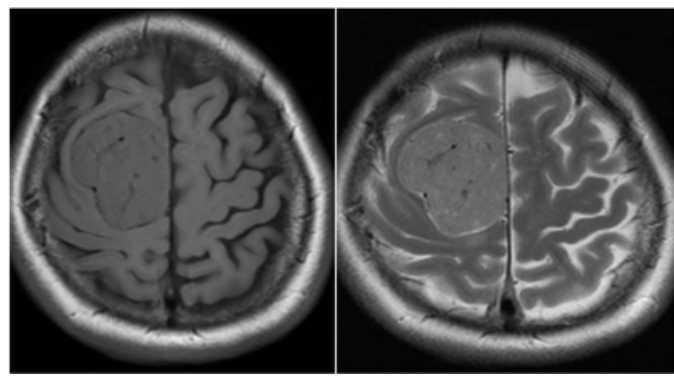

A B

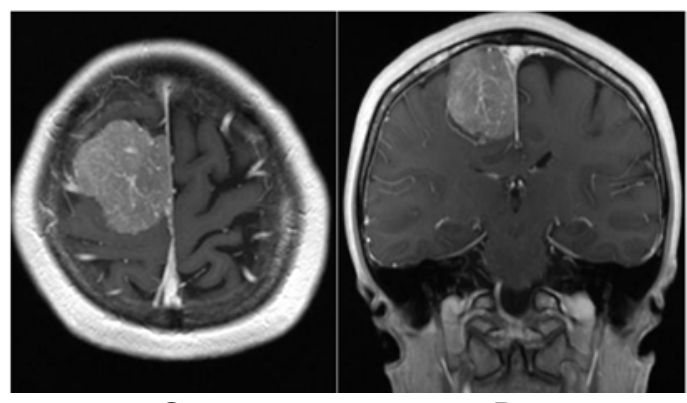

$\mathrm{C}$

Figure 22 - MRI Brain: axial cut T1WI [a], axial T2WI [b], axial T1WI with contrast [c], coronal cut T1WI with contrast [d] showed gross total resection of middle third SSS right parasagittal meningioma grade II on Sindou's classification

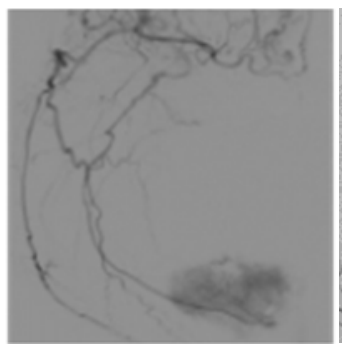

A

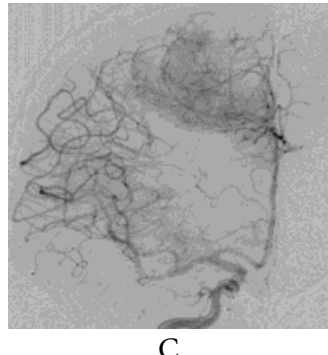

C

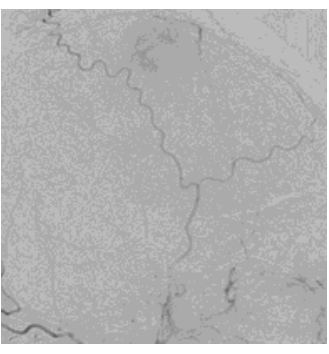

B

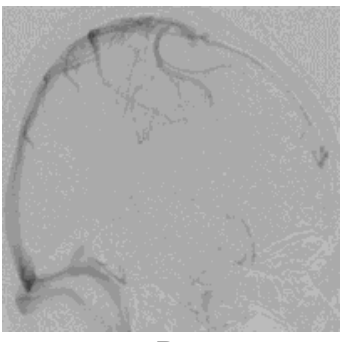

$\mathrm{D}$
Figure 23 - angiography for the same case Right external carotid angiography [a], left external carotid angiography [b]. Right internal carotid angiography [c] Venus phase [d] revealed high feeder flow from right internal carotid artery plus both external carotid also and the SSS was not occluded

We used supine position for the patient, head was fixed at 3 points in the midline then head tilted to the other side. Under the microscope we devascularised the tumor by using electrocautery of the feeders from Right ECA, Right \&Left ICA and tumor draining veins with preservation of brain parenchyma draining veins above the tumor capsule toward the SSS then we excised the meningioma internally piecemeal followed by removing the tumor part that adherent to the SSS at the end and got Simpson Grade 2 which appeared in postoperative MRI Brain images (Figure 24) postoperatively the weakness worsen for few days then gradually improved. 


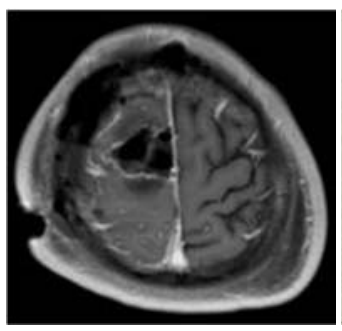

A

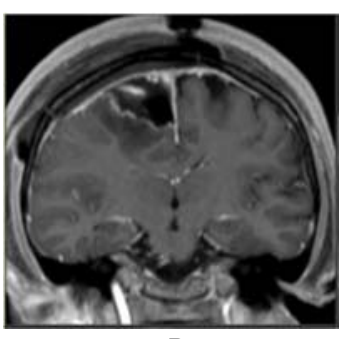

B

Figure 24 - MRI Brain: axial T1WI with contrast [a], coronal cut T1WI with contrast [b] showed No apparent residual tumor

\section{Results}

23 patients had parasagittal meningioma underwent surgical tumor resection in neurosurgery dept., Mansoura University Hospital in the period that began in 2010 and ended in 2016

The patient's age varied between 64-35 years and the median age was 49,2 years. 16 females \& 7 males. Right in 12, left in 9 and bilateral involvement in 2 cases.

The presenting symptoms are mentioned in Table 1.

TABLE I

Presenting symptoms of 24 Parasagittal meningioma cases

\begin{tabular}{|l|l|l|l|l|}
$\begin{array}{l}\text { Presenting } \\
\text { symptom }\end{array}$ & $\begin{array}{l}\text { Anterior } \\
\mathbf{1} / \mathbf{3}^{\text {rd }}\end{array}$ & $\begin{array}{l}\text { Middle } \\
\mathbf{1} / \mathbf{3}^{\text {rd }}\end{array}$ & $\begin{array}{l}\text { Posterior } \\
\mathbf{1} / \mathbf{3}^{\text {rd }}\end{array}$ & \multicolumn{2}{|l|}{} \\
\hline $\begin{array}{l}\text { Motor } \\
\text { weakness }\end{array}$ & 0 & 4 & 1 & 5 \\
\hline epilepsy & 3 & 2 & 1 & 6 \\
\hline headache & 6 & 3 & 1 & 10 \\
\hline
\end{tabular}

\begin{tabular}{|l|l|l|l|l|}
\hline Dizziness & 1 & 0 & 0 & 1 \\
\hline $\begin{array}{l}\text { Abnormal } \\
\text { gait }\end{array}$ & 1 & 0 & 0 & 1 \\
\hline
\end{tabular}

The meningiomas category in these patients, according to Sindou classification, are summarized in Table 2.

\section{TABLE II}

\begin{tabular}{|c|c|c|c|c|c|c|}
\hline $\begin{array}{l}\text { Meningioma } \\
\text { location }\end{array}$ & $\begin{array}{l}\text { Catego- } \\
\text { ry I }\end{array}$ & $\begin{array}{l}\text { Catego- } \\
\text { ry II }\end{array}$ & $\begin{array}{l}\text { Catego- } \\
\text { ry III }\end{array}$ & $\begin{array}{l}\text { Catego- } \\
\text { ry IV }\end{array}$ & $\begin{array}{l}\text { Catego- } \\
\text { ry V }\end{array}$ & $\begin{array}{l}\text { Catego- } \\
\text { ry VI }\end{array}$ \\
\hline $\begin{array}{l}\text { Anterior } \\
1 / 3^{\text {rd }}\end{array}$ & 2 & 3 & 2 & 3 & - & 2 \\
\hline Middle $1 / 3^{\text {rd }}$ & 3 & 1 & 1 & - & 2 & 1 \\
\hline $\begin{array}{l}\text { Posterior } \\
1 / 3^{\text {rd }}\end{array}$ & 1 & - & - & - & - & 2 \\
\hline total & 6 & 4 & 3 & 3 & 2 & 5 \\
\hline
\end{tabular}

8 cases had bone hyperostosis and Calvarial bone invasion that revealed by images.

15 cases had gross total tumor excision (Simpson grade I or II) while 8 cases showed partial tumor removal (Simpson grade III or IV). The tumor size was estimated by measuring the meningioma three dimensions in the images (modified ellipsoid volume: $\left.A^{*} B^{\star} C / 2\right)$. The parasagittal meningioma average volume was approximately $57.2 \mathrm{~cm}^{3}$. The histopathology of these cases of (PSM) was grade 1 in 18 cases (78.3\%), 3 cases atypical meningioma ( $13 \%)$ and 2 cases was malignant grade $(8.7 \%)$ (Figures 25, 26, 27) 


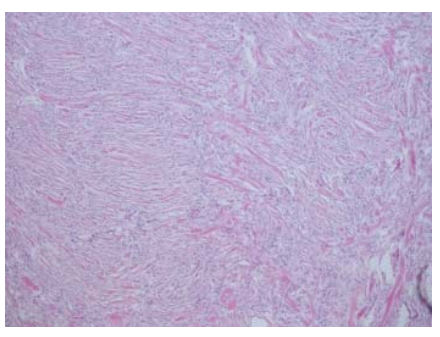

A

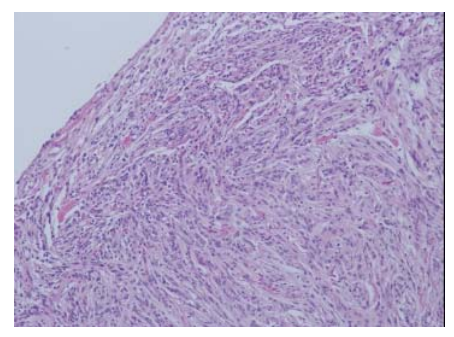

B

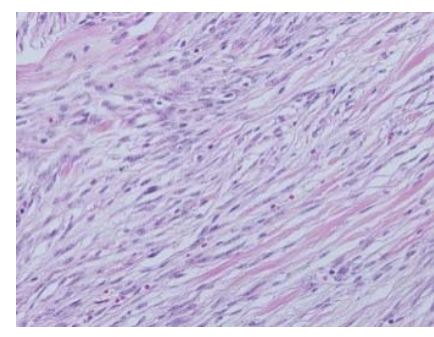

C

Figure 25 - HE films of G 1 PSM: A - X 40 magnification; B - X 100; C - X 200 show criteria of meningioma

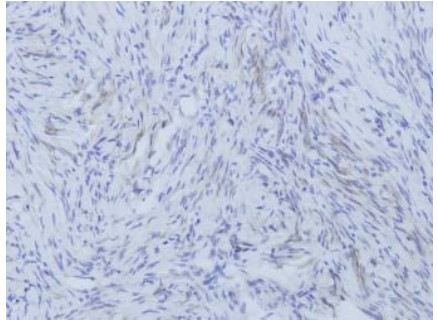

A

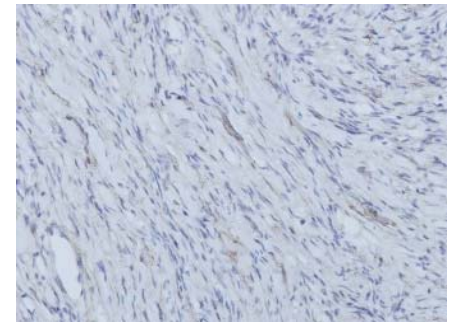

B

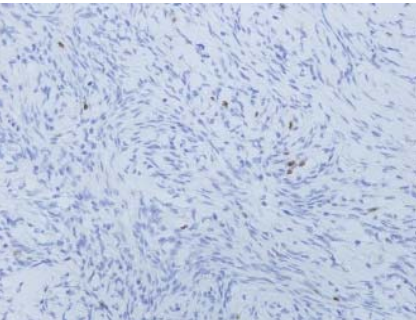

$\mathrm{C}$

Figure 26 - Immune stain for a case of PSM: A - EMA (+vet); B - Vimentin (+); C - MIB-1 (+) 2\%

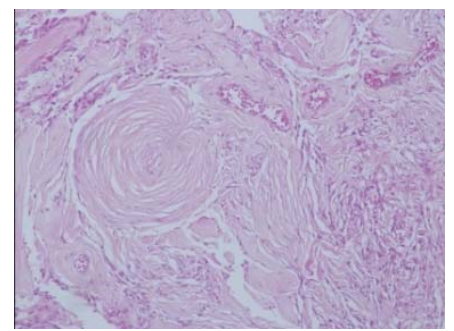

Figure 27 - HE of invaded bone film by meningioma cells in cases of PSM

Recurrence appeared in 4 cases $(17.4 \%)$ plus two mortality cases. Our patient's postoperative complication in relation to meningioma Sindou classification is mentioned in Table 3.

\begin{tabular}{|c|c|c|c|c|c|c|}
\hline complications & Category I & Category II & $\begin{array}{l}\text { Category } \\
\text { III }\end{array}$ & $\begin{array}{l}\text { Category } \\
\text { IV }\end{array}$ & Category V & Category VI \\
\hline Brain swelling & - & - & & & 1 & 2 \\
\hline CSF Leak & - & & 1 & & 1 & \\
\hline $\begin{array}{l}\text { New Neurological } \\
\text { deficit }\end{array}$ & 1 & - & - & 2 & 1 & 2 \\
\hline Hemorrhage & & & 1 & 1 & & \\
\hline Mortality & & & & & & 2 \\
\hline systemic & 1 & & - & & 1 & \\
\hline recurrence & & & 2 & 1 & 1 & \\
\hline
\end{tabular}


Distribution of the complication in relation to the parasagittal meningioma location on SSS (Table 4).

\begin{tabular}{|c|c|c|c|}
\hline complications & Anterior $1 / 3^{\text {rd }}$ & Middle $1 / 3^{\text {rd }}$ & Posterior $1 / 3^{\text {rd }}$ \\
\hline Behavior changes & 1 & & \\
\hline Motor weakness & & 3 & \\
\hline Visual impairment & & & 1 \\
\hline Dysphasia & & 1 & \\
\hline Brain edema & 1 & 1 & 1 \\
\hline Infection & 1 & 1 & \\
\hline CSF Leak & 2 & - & - \\
\hline Hemorrhage & 1 & 1 & - \\
\hline mortality & 1 & - & 1 \\
\hline Recurrence & 2 & 1 & 1 \\
\hline
\end{tabular}

We observed 5 patients suffered from new neurological impairment: one has behavior changes which was aggressive early postoperative then gradually improved within limit leaving permanent personality changes as a result of venous infarction during Anterior $1 / 3^{\text {rd }}$ SSS parasagittal tumor surgical removal. 3 patients with middle SSS $1 / 3^{\text {rd }}$ Parasagittal meningioma experienced motor weakness ( 2 category IV \& 1 category VI) one patient who had posterior $1 / 3^{\text {rd }}$ Parasagittal meningioma developed contralateral hemianopia with central vision sparing postoperatively. One patient suffered from dysphasia as a result of parasagittal meningioma on the middle $1 / 3^{\text {rd }}$ of SSS that improved gradually. All of them developed venous infarction due to SSS impairment or due to Venus collateral injury.

Aggressive brain edema developed in 3 (1 grade V \& 2 grade VI) according to Sindou classification but according to the tumor location ( 1 anterior $1 / 3^{\text {rd }}, 1$ middle $1 / 3^{\text {rd }} \&$ posterior $1 / 3^{\text {rd }}$ ) as a result of massive Venus infarction caused by collateral veins occlusion or SSS impairment. Two died within few days in spite of decompressive surgery and the last one lived suffered from serious neurological deficit and permanent sever disability. Two patients suffered from hemorrhage post operatively ( 1 of middle $1 / 3^{\text {rd }}$ tumor and the other of posterior $1 / 3^{\text {rd }}$ parasagittal meningioma) the first have been managed surgically and the other passed conservatively

The operated meningioma of the SSS middle $1 / 3^{\text {rd }}$ (SSS segment between coronal and lambdoid suture) had highest incidence of neurological impairment 4 cases. Two of them show some improvement within few weeks. Behavior changes was detected on operated meningioma of anterior $1 / 3^{\text {rd }}$. the visual impairment as post-operative sequela of operated posterior $1 / 3^{\text {rd }}$ parasagittal meningioma improved lightly within few months. All of these neurological complications appeared as a result of SSS occlusion partially or total and or as a result of SSS collateral veins (that creeped on tumor capsule) obstruction due to intraoperative lacerations, coagulation to stop bleeding or 
post-operative block. So, may administration of low molecular weight heparin after 36 hours postoperatively will reduce the venous obstruction complications.

The leak of CSF was detected in two cases and treated conservatively. Infection appeared in one case and treated with I.V. antibiotic till blood culture \& swap culture result had been obtained. We switched to appropriate antibiotic.

The recurrence was observed in four cases during follow up.

\section{Discussion}

The parasagittal meningiomas was first described by Cushing and Eisenhardt as meningiomas that attached to SSS without brain tissue separating it from the sinus. [3] In these cases, the SSS might be invaded by the tumor in variable degree. These tumours primary management modality according to the literatures varied between surgical excision and radiosurgery. [2] We adopt operative removal as primary treatment for parasagittal meningioma because many evidences in scientific papers mentioned higher incidence of brain swelling with its sequelae after radiation due to delayed collateral veins blocking. The optimum surgical procedure for parasagittal meningioma to remove it totally with minimum complication still controversy. [14] neurosurgeons like Brotchi and Sindou recommended putting the patients in semi sitting position to permit a free Venus drainage from the head to reduce the brain edema that facilitate the tumor resection with minimal brain parenchymal injury $[2,18]$. We adopt this technique in addition to use the gravity to get more space for surgical manipulation with minimal brain retraction. the drawback of this position is higher incidence of air embolism. We used a Central Venus Line $(\mathrm{CV}) \& \mathrm{CO}_{2}$ detector to early detection and management of this serious position related complication.

We adopt wide craniotomy flap to better visualization of SSS both sides in addition to collateral veins that creeping in tumor capsule toward SSS which its preservation (particularly those of Rolandic brain territory) have a crucial role in post-operative Venus infarction avoidance.[9] During surgery it relatively difficult to determine which vessels can be sacrificed safely in addition to misinterpretation of cortical veins size because in large tumours may appeared smaller than its real caliber as a result of the vessels stretch over the tumor capsule. This concept mad us leaving some small tumors parts around the large collateral veins around SSS. We used galea capitis patch or fascia lata graft to close the dural defect in most cases as we believed it gave better results with less infection rate and adequate heeling. Sometimes we adopt abdominal fat to help in closing and in forcing the defect closure $[5,10,11]$.

The complications in our series was more frequent in surgery of SSS anterior $1 / 3^{\text {rd }}$ meningiomas ( 9 of 12 cases: one of them died) then middle $1 / 3^{\text {rd }}(8 / 9$ patients) patients and the least was in those of SSS posterior $1 / 3^{\text {rd }}$. We can have explained that by impairment of essential Venus collateral that was well developed in the high grade of Sindou classification tumors as a result of extensive SSS invasion that lead to massive edema or 
extensive Venus infarction. [11,12] And this was opposite to what mentioned by SchmidElsaesser who stated that the anterior $1 / 3^{\text {rd }}$ parasagittal meningioma surgery could be passed well without any consequences. The explanation of our results referred to: anatomical variations of draining brain area by anterior $1 / 3^{\text {rd }}$ of SSS and presence of vital collateral bridging veins [17]. Adequate interpretation of preoperative MRI T2WE \& traditional Angiography may give vital information about SSS patency, tumor relation to bridging veins such as Rolandic \& labbe and collaterals. The favor of good prognosis after surgery was: complete occlusion of SSS by tumor, patent Rolandic \& labbe veins that did not involve by the tumor plus absence of hypertrophied collaterals. [10,11]

We believed that the primary surgery for parasagittal meningioma is highly significant in its progression and that goes with many literatures like what was mentioned by Sindou, Pradilla et al, Raza et al. and Alverni even with reconstruction of SSS gave good outcome with low mortality and recurrence rate $[15,16,18]$. While other authorities like DiMeco et al [4], Black et al. [1] and Sughrue et al. [19]. They postulated that the residual small tumor volume which invade SSS will not increase in short period because the most common histopathological grade was benign one and if it happened they prefer to shift to radiotherapy. In the light of this concept: The cornerstone cause of tumor relapse is incapability to remove it in the first surgical procedure as mentioned by Minimanoff et al [13]. The recurrence in our study discovered in 4 cases $(17.4 \%)$ which presented in the international series that varied between (32\%4\%) [1,19]. Table 5 below summarized collected data of Parasagittal Meningioma surgical management results studies.

TABLE V

Showed collected data of Parasagittal Meningioma surgical management results studies

\begin{tabular}{lccc}
\hline Author/year & Cases & $\begin{array}{c}\text { Mortality } \\
(\%)\end{array}$ & $\begin{array}{c}\text { Recurrence } \\
(\%)\end{array}$ \\
\hline Hoessly and Olivecrona /1953 & 196 & 12.3 & 6 \\
\hline Simpson $20 / 1957$ & 107 & - & 19 \\
\hline Logue $5 / 1975$ & 91 & 4.4 & 11 \\
\hline Bonnal and Brotchi /1978 & 21 & 4.7 & 14 \\
\hline Giombini et al./1984 & 243 & - & 17.7 \\
\hline Dimeco et al./2008 & 108 & 1.9 & 13.9 \\
\hline Sindou and Alvernia /2000 & 100 & 3 & 4 \\
\hline Colli et al./2006 & 53 & 1.9 & 32.7 \\
\hline Raza et al./2010 & 61 & 1.5 & 11
\end{tabular}


Surgical mortality in our (PSM) cases was two cases (8.7\%). the scientific paper mentioned that the mortality rate was over $40 \%$ in old series that reduced to be less than $2 \%$ in newest papers and we referring this excellent result to adoption of microscopic techniques, neurophysiological study application, navigator usage and most important cause was early detection in smaller size but in our society may we see these cases with a very large volumes that invade the arachnoid plane and important bridging veins [6]

\section{Conclusion}

Through our series we could detect cardinal factors in prognosis of these cases which included: tumor size, histology, preoperative identification of the venous collateral and preservation of it in the surgical maneuver. The meticulous microscopic surgical technique can augment this goal.

\section{Correspondence}

Ashraf ElBadry, M.D., IFAANS, Osaka University fellow

Address: Department of neurological surgery,

Faculty of Medicine, Mansoura University

Hospital, EGYPT

Email address: ashrafbadry@hotmail.com

ashrafbadry@mans.edu.eg

Cell phone: $+201111300033-+201223477444$

\section{References}

1. Black PM, Zauberman S. Parasagittal and falx meningiomas. Meningiomas: a comprehensive text. In: Palmir MN, Black PM, Fallbusch R (Eds). China: Saunders; 2010. p. 349-354.
2. Brotchi J. Should we pursue superior sagittal sinus grafting in parasagittal meningiomas in 2013? World Neurosurg. 2014;82:325-6.

3. Cushing H. Meningiomas their classification regional behavior. Life history and surgical end results. Springfield 1938:404-505.

4. Di Meco F, Li KW, Casali C, Ciceri E, Giombini S, Filippini G, et al. Meningiomas invading the superior sagittal sinus: Surgical experience in 108 cases. Neurosurgery. 2004;55:1263-72.

5. Di Vitantonio H, De Paulis D, Del Maestro M, Ricci A, Dechordi SR, Marzi S, et al. Dural repair using autologous fat: Our experience and review of the literature. Surg Neurol Int. 2016;7(Suppl 16):S463-8. [PMC free article] 6. Hancq S, Baleriaux D, Brotchi J. Surgical treatment of parasagital meningiomas. Semin Neurosurg 2003;14:203210.

7. Lee JM, Jung S, Moon KS, Seo JJ, Kim IY, Jung TY, et al. Preoperative evaluation of venous systems with 3dimensional contrast-enhanced magnetic resonance venography in brain tumors: Comparison with time-offlight magnetic resonance venography and digital subtraction angiography. Surg Neurol. 2005;64:128-33. 8. N, Malikov S, Fuentes S, Pech-Gourg G, Graillon T, Dufour H. Superior sagittal sinus reconstruction using a femoral venous graft after total removal of a meningioma. Case report. Neurochirurgie. 2013;59:43-6.

9. Nussbaum ES, Defillo A, Janjua TM, Nussbaum LA. Microvascular Repair of an Injured Cortical Draining Vein. Surg Neurol. 2009;72:530-1.

10. Mantovani A, Di Maio S, Ferreira MJ, Sekhar LN. Management of meningiomas invading the major dural venous sinuses: Operative technique, results, and potential benefit for higher grade tumors. World Neurosurg. 2014;82:455-67.

11. Mathiesen T, Pettersson-Segerlind J, Kihlström L, Ulfarsson E. Meningiomas engaging major venous sinuses. World Neurosurg. 2014;81:116-24.

12. Maxwell RE, Chou SN. Parasagittal and falx meningioma. Operative neurosurgery. In: Schmidek HH, Sweet WH (Eds). 2nd edition. Orlando: Grune Stratton; 1988 p. 563-570.

13. Minimanoff RO, Dosoretz DE, Linggood RM, Ojemann RG, Martuza RL: Meningioma: Analysis of recurrence and progression following neurosurgical resection. J Neurosurg 1985; 62:18-24 
14. Pires de Aguiar PH, Aires R, Maldaun MV, Tahara A, de Souza Filho AM, Zicarelli CA, et al. Is sagittal sinus resection in falcine meningiomas a factor of bad surgical outcome? Surg Neurol Int. 2010;1:64.

15. Pradilla G, Solero CL, Dimeco F. Parasagittal meningiomas. Al-mefty's meningiomas. In: De Monte F, Mc Dermott MW, Al-Mefty O (Eds). New York: Thieme; 2011. p. 142-160.

16. Raza SM, Gallia GL, Brem H, Wegart JD, Long DM, Olivi A. Perioperative and long tern outcomes from management of parasagittal meningiomas invading the superior sagittal sinus. Neurosurgery 2010;67:885-893.

17. Schmid-Elsaesser R, Steiger HJ, Yousry T, Seelos KC,

Reulen HJ. Radical resection of meningiomas and arteriovenous fistulas involving critical dural sinus segments: experience with intraoperative sinus pressure monitoring and elective sinus reconstruction in 10 patients. Neurosurgery 1997;41:1005-1016

18. Sindou M, Auque J, Jouanneau E. Neurosurgery and the intracranial venous system. Acta Neurochir Suppl. 2005;94:167-75.

19. Sughrue ME, Rutkow Ski, Gopal SG, et al. Results with judicious modern neurosurgical management of parasagittal and falcine meningiomas. J Neurosurg 2011;114:731-737. 